\title{
Formulation and in-vitro Evaluation of Oral Captopril Bioadhesive Delivery System
}

\author{
Mohamed Dawoud ${ }^{1,2,}$, Fahima Hashem² \\ ${ }^{1}$ Department of Pharmaceutics, Faculty of Pharmacy, Umm Al Qura, University, Holy Makkah, KSA. \\ 2Department of Pharmaceutics and Industrial Pharmacy, Faculty of Pharmacy, Helwan-University, Cairo, EGYPT.
}

\begin{abstract}
Background: Captopril is considered as the drug of choice in the treatment of hypertension and congestive heart failure. It has a very short duration of action and a biological half-life of 1-2 hr. This requires its administration in 2-3 times daily which is not convenient for the management of a chronic disease like hypertension. Objectives: Captopril is unstable at the alkaline $\mathrm{pH}$ of the gastrointestinal tract. Therefore, it is difficult to be delivered orally in a sustained release formulation. This defect can be overcome by using bioadhesive or floating delivery systems which could increase the residence time of the drug in the stomach. Methods: Different formulations of bioadhesive chitosan microspheres containing captopril were prepared using the cross-linking method. Characterization of these microspheres was performed by measuring percent yield, particle size, swelling and bioadhesive properties, drug content and in-vitro release of captopril. Results: Chitosan microspheres prepared from $2 \%$ high molecular weight chitosan in acetic acid with $5 \mathrm{ml}$ glutaraldehyde and a cross-linking time of $3 \mathrm{hr}$ gave the highest yield percent $(83 \%)$, the highest entrapment efficiency $(55 \%)$ and sustained release over $8 \mathrm{hr}$, compared with other examined formulations of chitosan. The release kinetics from all the prepared microspheres were diffusion-controlled mechanism and the drug release from microspheres was dependent on its concentration. Conclusion: In conclusion, chitosan microspheres with their particle size and release behavior seem to be a good carrier for captopril.

Key words: Chitosan, Microspheres, Bioadhesion, Captopril, In-vitro release.
\end{abstract}

\section{INTRODUCTION}

Captopril is the first orally active angiotensin converting enzyme inhibitors and still the gold standard in the world of angiotensin converting enzyme inhibition. It has a very short duration of action. Therefore, its clinical efficacy in treatment of hypertension is achieved only through two- or three-times daily administration. ${ }^{1,2}$

On the other hand, previous studies have shown that, the degradation of captopril takes place in the alkaline regions of the Gostrointestinal Tract (GIT). ${ }^{3}$ Therefore, it is difficult to be delivered orally in a sustained release formulation which requires drugs showing no difference in absorption during the passage through the gastrointestinal tract.
This defect can be overcome by increasing the residence time of the drug delivery system in the stomach. Among the methods that could be employed to prolong gastric emptying time and improve drug bioavailability is the use of bioadhesive and floating systems. ${ }^{4}$

Several trials have been developed to increase the residence time of captopril in the stomach. Nur and Zhang prepared captopril floating and / or bioadhesive tablets using HPMC 4000 with carbopol 934p. ${ }^{5}$ However, all these trials produced single-unit systems which showed fluctuating bioavailability due to variation in gastric emptying time.
Submission Date: 19-11-2019; Revision Date: 06-02-2020; Accepted Date: 30-04-2020

DOI: 10.5530/ijper.54.2s.76 Correspondence: Dr. Mohamed Dawoud Department of Pharmaceutics, Faculty of Pharmacy, Umm Al Qura University, Holy Makkah, KSA.

Phone: +966546116057 E-mail: Mohameddawoud3@ yahoo.com

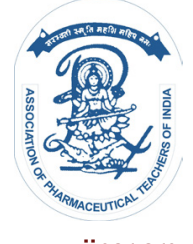

www.ijper.org 
To overcome this problem, multiple unit microparticulate systems (microspheres, microbeads, granules or pellets) have been developed. Such microparticulate or multipleunit dosage forms can disperse as individual units in the stomach and so become widely distributed in the gastric medium. For this reason, they have a longer reproducible gastric residence time and less absorption variability than single unit systems. ${ }^{6}$ In addition, these microparticulate systems when administered orally, may be able to penetrate the deep mucous layer and prolong the residence time at the mucin-epithelial cell surface, thereby, improving the oral absorption of drugs and reducing its exposure to enzymatic digestion. Thus, it may be possible to design a once daily dose to decrease the frequency of administration of the drug and improve patient compliance. ${ }^{6}$

Microspheres are defined as homogenous, monolithic particles in the size range of about $0.1-1000 \mu \mathrm{m}$ and are widely used as drug carriers for controlled release. These microspheres have a significant importance in the biomedical application. Administration of a drug in the form of microspheres usually improves treatment by localizing the active substance at the site of action and prolonging the drug release. Furthermore, sensitive drugs such as peptides and proteins may be protected against chemical and enzymatic degradation when entrapped in microspheres. ${ }^{7,8}$ When preparing controlled release microspheres, the choice of the optimal method is of great importance for efficient entrapment of the active substance.

Chitosan is a naturally occurring biopolymer made up of $B(1,4)$ - linked glucosamine units that is produced by alkaline deacetylation of chitin extracted from shells of crabs, shrimps and krills. ${ }^{9}$ Since chitosan exhibits favorable biological properties such as nontoxicity, ${ }^{10}$ biocompatibility, ${ }^{11,12}$ and biodegradability, ${ }^{13}$ it has attracted great attention in the pharmaceutical and biomedical fields.

Pharmaceutically, chitosan is used in controlled drug delivery systems, ${ }^{14}$ mucoadhesive dosage form, ${ }^{15,16}$ improved peptide delivery ${ }^{17}$ and gene delivery. ${ }^{18}$

The aim of this work was to formulate chitosan microspheres containing captopril as a bioadhesive delivery system. In addition, the effect of different process variables on the properties of chitosan microspheres and on in-vitro drug release was investigated.

\section{MATERIALS AND METHODS}

\section{Materials}

Captopril was supplied from Bristol Myers Squibb Egypt, Chitosan (high molecular weight 600,000 with viscosity of $400 \mathrm{cps}$ and low molecular weight 70,000 with viscosity $100 \mathrm{cps}$ ), span 85, glutaraldehyde, acetic, lactic, propionic, citric and formic acids, methanol and $\mathrm{n}$-hexane were purchased from Sigma Chemical company (ST. Louis, M.O, USA).

\section{Preparation of chitosan microspheres containing captopril:}

Chitosan microspheres were prepared by the cross-linking method described before. ${ }^{19} 200 \mathrm{mg}$ of chitosan $(2 \% \mathrm{w} / \mathrm{v})$ were dissolved in $10 \mathrm{ml}$ of $5 \%$ aqueous acid solution. $100 \mathrm{mg}$ of captopril $(1 \% \mathrm{w} / \mathrm{v})$ were added to chitosan solution. Then drug/Chitosan solution was poured into $75 \mathrm{ml}$ of sunflower oil containing $1.5 \mathrm{ml}$ of span $85(2 \%$ $\mathrm{v} / \mathrm{v}$ ) as an emulsifier at room temperature. The suspension was emulsified by stirring at $700 \mathrm{rpm}$ for $15 \mathrm{~min}$ using mechanical stirrer (Ika, Labor Technik, RW 20, Germany). The formed droplets were solidified by adding $5 \mathrm{ml}$ glutaraldehyde (cross-linking agent) at three intervals each $30 \mathrm{~min}$ with continuous stirring for $3 \mathrm{hr}$. At the end, the microspheres suspension was filtered, washed three times with $\mathrm{n}$-hexane and dried in an oven at $40^{\circ} \mathrm{C}$ for $24 \mathrm{hr}$. The different formulation variables of the cross-linked chitosan microspheres containing captopril are illustrated in Table 1.

\section{Determination of the yield percent}

The prepared microspheres were collected and weighed. The percent yield was determined by dividing the weight of the collected microspheres by the weight of the total amount of all the components used in the preparation of the microspheres. ${ }^{20,21}$

\section{Particle size analysis}

Particle size was determined by the sieve analysis method. Microspheres were shaken mechanically on a set of standard sieves with the following descending mesh sizes 800, 710, 560, 450, 224, 150 and $63 \mu \mathrm{m}$ for 15 min using analytical sieve shaker (Retsch, AS 200 Germany). Each fraction remaining on the sieve was weighed and the mean microspheres particle size as well as the highest particle size distribution were determined.

\section{Determination of entrapment efficiency}

The percentage drug content for each microsphere was determined by suspending $10 \mathrm{mg}$ of the microspheres in $20 \mathrm{ml}$ methanol at room temperature for $24 \mathrm{hr}$ for complete extraction of entrapped drug from the microspheres. The suspension was centrifuged at $2000 \mathrm{rpm}$ for 5 min (Hermle, Z 200 A, Germany). $1 \mathrm{ml}$ of the supernatant solution was diluted with $4 \mathrm{ml}$ of $0.05 \mathrm{M}$ sodium hydroxide and its absorbance determined spectrophotometrically at $238 \mathrm{~nm}$ (Perkin Elmer, type 


\begin{tabular}{|c|c|c|c|c|c|}
\hline \multicolumn{6}{|c|}{ Variables } \\
\hline Formula & Chitosan Mol.Wt. & $\begin{array}{c}\text { Chitosan } \\
\text { concentration: } \\
(\% \mathrm{w} / \mathrm{v})\end{array}$ & $\begin{array}{c}\text { Amount of } \\
\text { glutaraldehyde }(\mathrm{ml})\end{array}$ & $\begin{array}{l}\text { Time of cross- } \\
\text { linking (hrs) }\end{array}$ & Acid \\
\hline $\mathrm{C} 1$ & High & 2 & 5 & 3 & Acetic \\
\hline $\mathrm{C} 2$ & Low & 2 & 5 & 3 & Acetic \\
\hline C3 & High & 1 & 5 & 3 & Acetic \\
\hline $\mathrm{C} 4$ & High & 1.5 & 5 & 3 & Acetic \\
\hline C5 & High & 2 & 1 & 3 & Acetic \\
\hline C6 & High & 2 & 3 & 3 & Acetic \\
\hline $\mathrm{C} 7$ & High & 2 & 5 & 1.5 & Acetic \\
\hline C8 & High & 2 & 5 & 3 & Lactic \\
\hline $\mathrm{C9}$ & High & 2 & 5 & 3 & Propionic \\
\hline C10 & High & 2 & 5 & 3 & Citric \\
\hline C11 & High & 2 & 5 & 3 & Formic \\
\hline
\end{tabular}

Lambda EZ 201, USA). The percentage of captopril entrapped within the microspheres can be calculated by applying the following equation:

$$
\begin{gathered}
\text { EE } \%=\frac{\begin{array}{l}
\text { Actual of captopril in } 10 \mathrm{mg} \\
\text { of the microspheres }
\end{array}}{\begin{array}{l}
\text { Theoretical amount of captopril in } \\
10 \mathrm{mg} \text { of the microspheres }
\end{array}} \times 100
\end{gathered}
$$

\section{In-vitro release studies of captopril from microspheres}

Release of captopril from microspheres was carried out using USP rotating paddle method at a stirring rate $50 \mathrm{rpm}$ (Hanson Research CA. USA). $50 \mathrm{mg}$ of microspheres were suspended in $200 \mathrm{ml} 0.1 \mathrm{~N}$ hydrochloric acid as a dissolution medium maintained at $37^{\circ} \mathrm{C} \pm 0.1$. At specified time intervals, $1 \mathrm{ml}$ sample was withdrawn and immediately replaced with equal volume of fresh medium. The samples were filtered through $0.45 \mu \mathrm{m}$ Millipore filter and then diluted with $4 \mathrm{ml}$ of $0.05 \mathrm{M}$ sodium hydroxide and allowed to set aside for $10 \mathrm{~min}$. The samples were assayed spectrophotometrically at $238 \mathrm{~nm}$ against a blank solution. The dissolution of each type of the prepared microspheres was carried out at three replicates against blank microspheres at the same time.

\section{Kinetics evaluation of the release data}

To investigate the possible mechanism of captopril release from the prepared microspheres, the release data was analyzed mathematically according to: Zero-order, First-order and Higuchi's equations using the equations that govern these models: ${ }^{22-24}$
Zero- order release kinetics: $(\mathrm{Qo}-\mathrm{Q})=\mathrm{f}(\mathrm{t})$

First- order release kinetics: $\ln (\mathrm{Qo}-\mathrm{Q})=\mathrm{f}(\mathrm{t})$

Higuchi-diffusion equation: $(\mathrm{Q} o-\mathrm{Q})=\mathrm{f}\left(\mathrm{V}_{\mathrm{t}}\right)$;

$$
\mathrm{dQ} / \mathrm{dt}=\mathrm{f}(1 / \mathrm{Q})
$$

Where:

$$
\begin{aligned}
& \text { Qo } \rightarrow \text { is the original amount (\%) of drug } \\
& \text { present in the tested samples } \\
& \mathrm{Q} \rightarrow \text { is the amount (\%) of drug released } \\
& \mathrm{t} \rightarrow \text { is the time }
\end{aligned}
$$

\section{Swelling properties}

$100 \mathrm{mg}$ of each type of microspheres was suspended in $10 \mathrm{ml}$ of $0.1 \mathrm{~N}$ hydrochloric acid in a graduated measuring cylinder. The microspheres were allowed to hydrate for 1, 4, 8 and $24 \mathrm{hr}$. Then the swelling volume was recorded and compared. The swelling volume was the water intake corresponding to $1 \mathrm{gm}$ of microspheres powder. ${ }^{25}$

\section{In-vitro determination of bioadhesive properties of the microspheres}

Microspheres were tested for bioadhesive properties using the previously described method. ${ }^{26} 50 \mathrm{mg}$ of microspheres were suspended in water. A segment of $3 \mathrm{~cm}$ from a rabbit stomach was cut and washed with saline to remove any debris. The suspension was poured drop wise on the mucosal side (mucous membrane) of a freshly excised rabbit stomach. The stomach segment with the microspheres was placed in a dessicator for $30 \mathrm{~min}$ to allow the hydration of microspheres. The mucosal layer bearing the adhered microspheres was washed with $0.1 \mathrm{~N}$ HCL. The drug content in the collected washings was determined and the ratio of 
the adhered to applied microspheres was calculated as percent adhesion.

\section{RESULTS AND DISCUSSION}

\section{Yield percent}

Figure 1 shows that all prepared microspheres gave a percent yield in the range between 70 and $83 \%$. It was found that the use of high molecular weight chitosan $\left(\mathrm{C}_{1}\right)$ in microsphere preparation gave a higher percent yield $(83 \%)$ than low molecular weight chitosan $\left(\mathrm{C}_{2}\right)$ which gave a percent yield of $75 \%$. The microspheres prepared with different concentrations of chitosan $1 \%$ $\left(\mathrm{C}_{3}\right), 1.5 \%\left(\mathrm{C}_{4}\right)$ and $2 \%\left(\mathrm{C}_{1}\right)$ showed different percent yields 76,81 and $83 \%$ respectively. As the molecular weight and concentration of chitosan increased, the viscosity of the matrix solution also increased which in turn increased the yield values and decreased the component loss during preparation. ${ }^{27}$

The results also illustrated that by increasing the volume of the cross-linking agent, glutaraldehyde from $1 \mathrm{ml}\left(\mathrm{C}_{5}\right)$, $3 \mathrm{ml}\left(\mathrm{C}_{6}\right)$ to $5 \mathrm{ml}\left(\mathrm{C}_{1}\right)$ the percent yields increased from 70 and 78 to $83 \%$ respectively. Furthermore, by increasing the cross-linking time from $1.5 \mathrm{hrs}\left(\mathrm{C}_{7}\right)$ to $3 \mathrm{hr}\left(\mathrm{C}_{1}\right)$ the percent yield was increased from 79 to $83 \%$. This effect may be referred to the increase in cross-linking between chitosan molecules which decreased the loss of the drug and chitosan during the preparation process. ${ }^{28}$ As shown in Figure 1 the use of different acids as solvents for chitosan also affected the percent yield. Acetic acid $\left(C_{1}\right)$ showed the highest percent yield $(83 \%)$, while citric acid $\left(\mathrm{C}_{10}\right)$ showed the lowest percent yield $(74 \%)$. This was referred to the high viscosity of chitosan in acetic acid solution as previously reported ${ }^{27,29,30}$ where it was found that $1 \%$ chitosan in $1 \%$ acetic acid gave a viscosity of 260 cps while $1 \%$ chitosan in $1 \%$ citric acid gave a viscosity of 35 cps.

In conclusion, the percent yield reported in all formulae was found to be dependent on the concentration of chitosan, its molecular weight, cross-linking amount, crosslinking time and type of acid used.

\section{Particle size analysis}

Analysis of the Particle size of the prepared microspheres showed that the size of chitosan microspheres was mainly affected by the viscosity of its solution. As seen in Figure 2, chitosan of high molecular weight $\left(\mathrm{C}_{1}\right)$ produced larger microspheres $(531 \mu \mathrm{m})$ than chitosan of low molecular weight $\mathrm{C}_{2}(364 \mu \mathrm{m})$. The increase in concentration of chitosan from 1\% $\left(\mathrm{C}_{3}\right), 1.5 \%\left(\mathrm{C}_{4}\right)$ to $2 \% \mathrm{w} / \mathrm{v}\left(\mathrm{C}_{1}\right)$ resulted in an increase in particle size from 336, 409 to $531 \mu \mathrm{m}$ respectively. This could be referred to the higher viscosity of the chitosan solutions obtained by using chitosan of high molecular weight and high concentration. These results were in agreement with previously reported data ${ }^{31}$ stating that particle size of chitosan microspheres is strongly dependent on its molecular weight and concentration.

Figure 3 shows the sieve size, which contained the highest amount of microspheres (highest frequency distribution $\mu \mathrm{m}$ ). The figure shows that, the majority of the microspheres prepared using different amounts of cross-linking agent $\left(\mathrm{C}_{1}, \mathrm{C}_{5}, \mathrm{C}_{6}\right)$ had the same particle size $(560 \mu \mathrm{m})$. Furthermore, the highest frequency distribution of formulae $C_{1}$ and $C_{7}$ prepared with different cross-linking time, was also the same. These

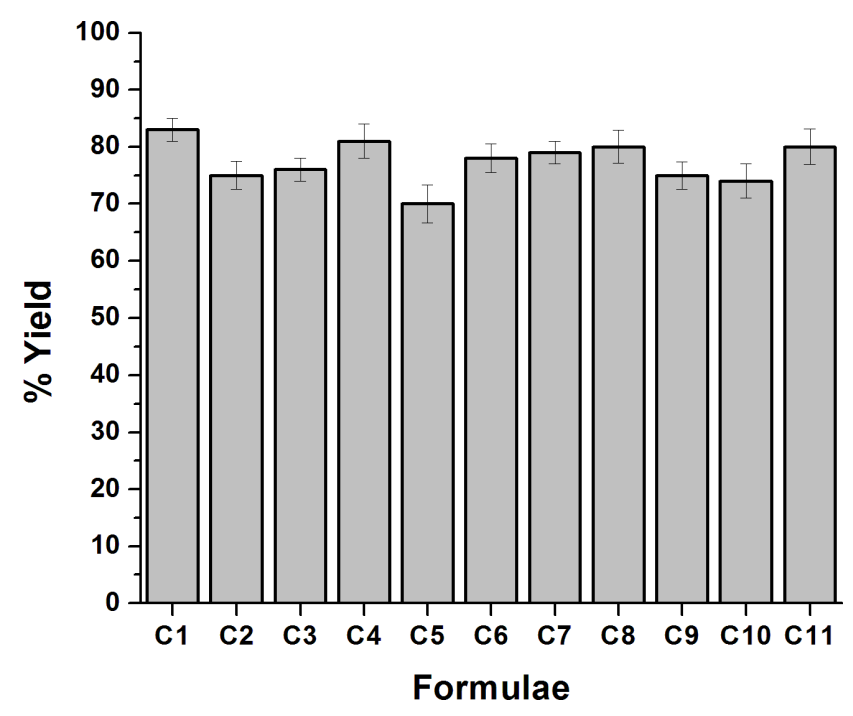

Figure 1: Percentage yield of the different chitosan microspheres $(n=3)$.

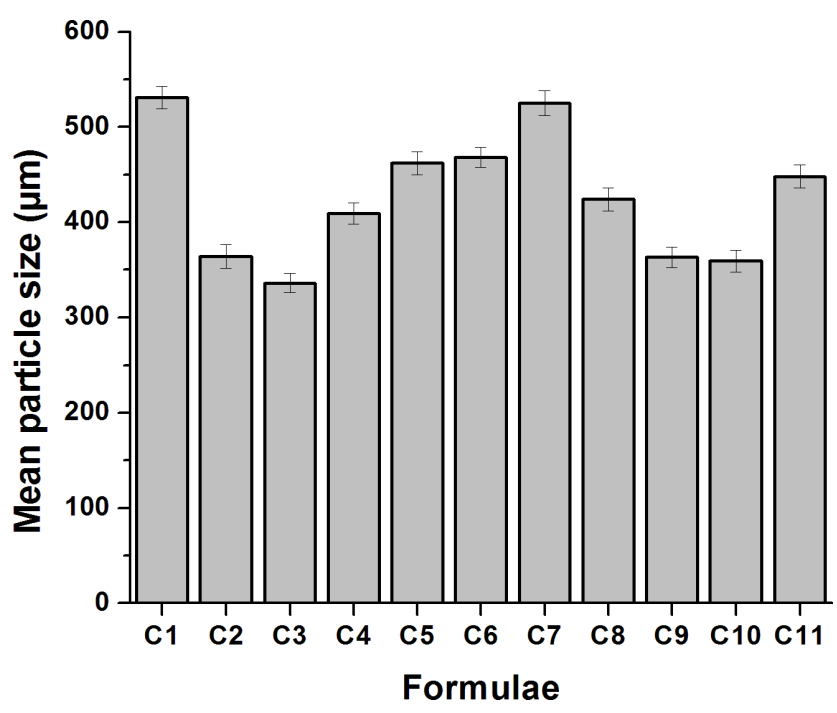

Figure 2: Mean particle size $(\mu \mathrm{m})$ of the different chitosan microspheres $(n=3)$. 


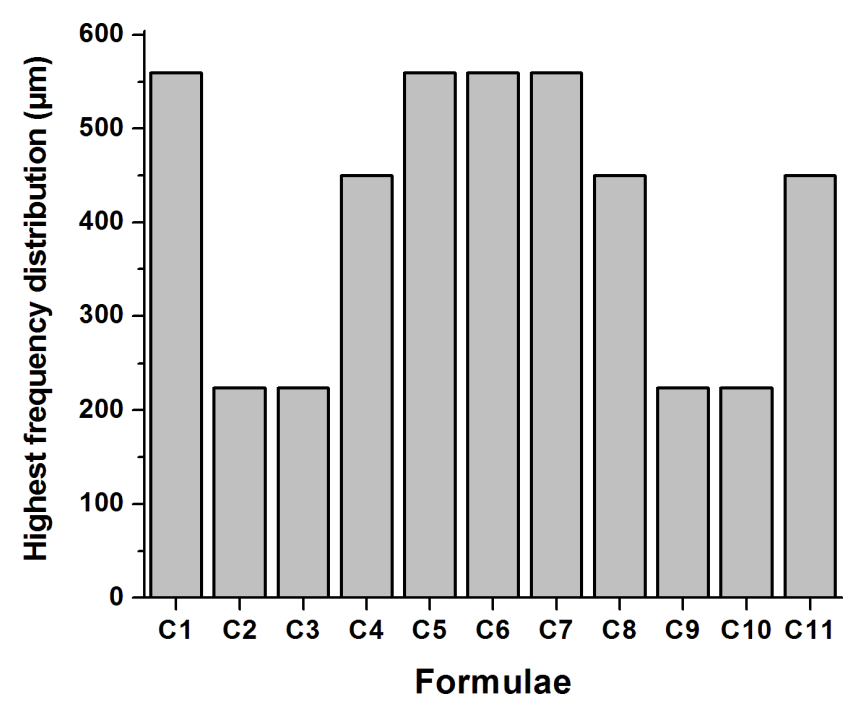

Figure 3: Highest frequency distribution for the particle size $(\mu \mathrm{m})$ of the different chitosan microspheres.

results could be attributed to the constant viscosity of chitosan solutions prepared with different cross-linking amounts and time. ${ }^{32,33}$ On the other hand, a larger particle size (560um) was produced when chitosan was dissolved in acetic acid $\left(\mathrm{C}_{1}\right)$ than when dissolved in lactic acid $\left(\mathrm{C}_{8}\right)$, propionic acid $\left(\mathrm{C}_{9}\right)$, citric acid $\left(\mathrm{C}_{10}\right)$ and formic acid $\left(\mathrm{C}_{11}\right)$ as illustrated in Figure 3. As mentioned before the viscosity of chitosan solution in acetic acid was higher than that of other acids used. This was explained previously ${ }^{27,34}$ where it was found that $1 \%$ chitosan in $1 \%$ acetic, lactic, propionic, citric and formic acid gave viscosity 260, 235, 195, 35 and 240 cps respectively.

\section{Incorporation efficiency}

All prepared chitosan microspheres produced a low percentage incorporation efficiency that did not exceed $55 \%$ as seen in Figure 4. Thanoo and his coworkers ${ }^{35}$ suggested that the low incorporation efficiency of a highly water-soluble drug is due to the rapid loss of the drug during the process of preparation. By comparing the difference in the molecular weight of chitosan dissolved in acetic acid, it was found that high molecular weight chitosan $\left(\mathrm{C}_{1}\right)$ gave higher entrapment efficiency (55\%) compared to low molecular weight chitosan $\mathrm{C}_{2}(37 \%)$.

When lactic acid $\left(\mathrm{C}_{8}\right)$, propionic acid $\left(\mathrm{C}_{9}\right)$, citric acid $\left(\mathrm{C}_{10}\right)$ and formic acid $\left(\mathrm{C}_{11}\right)$ were used instead of acetic acid, the percentage entrapment efficiency decreased from 55 to $50,48,47$ and $51 \%$ respectively. It was previously reported that the higher entrapment efficiency observed with high molecular weight chitosan dissolved in acetic acid is related to its higher viscosity which decreased the diffusion of the drug outside the microspheres. ${ }^{27,31}$

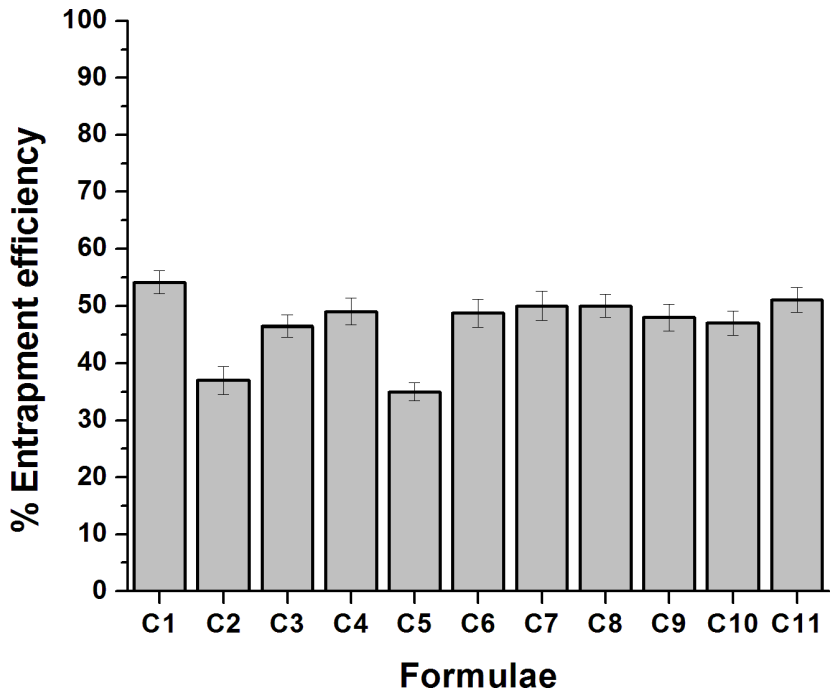

Figure 4: Percentage Entrapment efficiency of the different chitosan microspheres $(n=3)$.

It was also noticed that increasing the concentration of chitosan in acetic acid from $1 \%\left(\mathrm{C}_{3}\right), 1.5 \%\left(\mathrm{C}_{4}\right)$ to $2 \% \mathrm{w} / \mathrm{v}\left(\mathrm{C}_{1}\right)$ resulted in an increase in entrapment efficiency of captopril from 46.5, 49 to $55 \%$ respectively. This is probably due to the increased viscosity of chitosan solution prepared with a concentration of $2 \% \mathrm{w} / \mathrm{v}$. These results were in accordance with earlier reports made by Thanoo and Akbuga. ${ }^{19,35}$

From Figure 4, it could be observed that by increasing the amount of cross-linking agent from $1 \mathrm{ml}\left(\mathrm{C}_{5}\right), 3 \mathrm{ml}$ $\left(\mathrm{C}_{0}\right)$ to $5 \mathrm{ml}\left(\mathrm{C}_{1}\right)$, percentage entrapment efficiency increased from 35, 48.7 to 55\% respectively. Furthermore, increasing the cross-linking time from $1.5 \mathrm{hr}\left(\mathrm{C}_{7}\right)$ to 3 hrs $\left(\mathrm{C}_{1}\right)$ slightly improves percentage entrapment efficiency from 50.8 to $55 \%$. The above-mentioned results were attributed to the increase of the crosslinking between chitosan molecules which decreased drug loss during the preparation process. These results showed that the entrapment efficiency in all formulae was dependent on all the tested variables.

\section{In-vitro release of captopril from chitosan microspheres}

Figure 5 illustrates the effect of different formulation variables on the percentage of drug released in $0.1 \mathrm{~N}$ HCL. It was found that drug release from all the prepared chitosan microspheres was characterized by an initial rapid release of the drug (burst effect), followed by a slower release of the remaining drug.

The higher initial percentage of drug released from chitosan microspheres may be related to the location of some drugs within the pores and surface of the prepared microspheres which were rapidly released upon contact with the release medium. The slower 

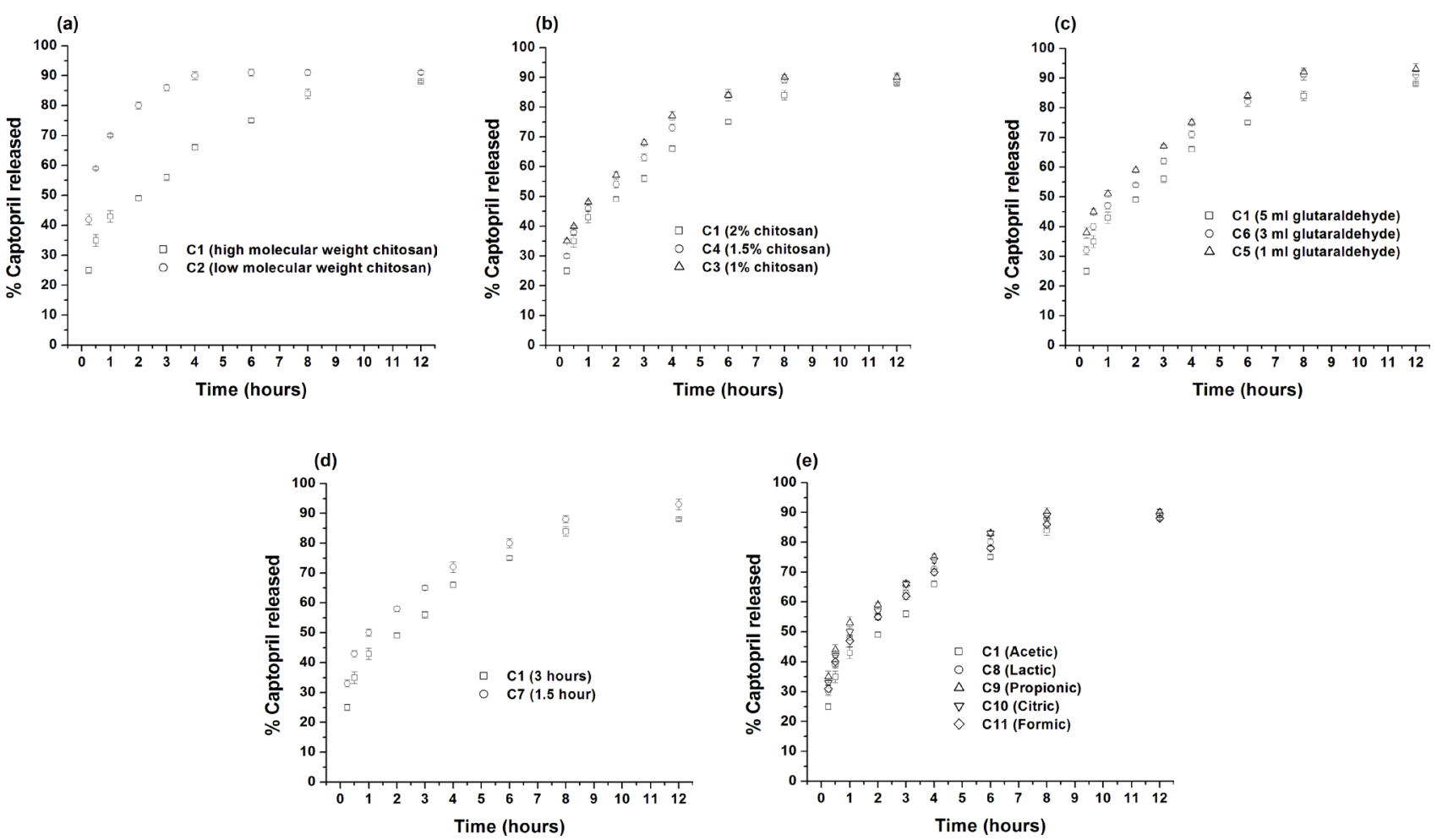

Figure 5: Effect of different variables on the percentage captopril released; a) chitosan molecular weight; b) chitosan concentration (w/v); c) amount of glutaraldehyde; d) time of cross-linking (hours); e) type of acid, $(n=3)$.

release rate might be attributed to the localization of the remaining drug within the polymer matrix. These results were in agreement with similar studies made by Denkbas $^{28}$ who reported that almost $50 \%$ of the loaded 5-flurouracil was released from the microspheres in the first hour. In our study about $43 \%$ was released at the same time $\left(\mathrm{C}_{1}\right)$.

The results also showed that the increase in the molecular weight of chitosan obviously decreased the percentage of drug release. Formula $C_{1}$ (high molecular weight) and $\mathrm{C}_{2}$ (low molecular weight) gave an initial percentage of drug release of 25 and $43 \%$ respectively after $15 \mathrm{~min}$. It could also be observed that the percentage of drug released after one hour was about 43 and $71 \%$ of the total drug loaded into the microspheres of formula $\mathrm{C}_{1}$ and formula $\mathrm{C}_{2}$ respectively.

Formula $\mathrm{C}_{2}$ showed complete drug release after $4 \mathrm{hr}$ $(90 \%)$ while the same percentage was obtained with formula $\mathrm{C}_{1}$ after $8 \mathrm{hr}$. Accordingly, the rate of drug release from the microspheres prepared with high molecular weight chitosan was slow in comparison with that prepared with low molecular weight chitosan (Figure 5a). This may be attributed to the higher viscosity of the gel layer of the polymer formed around the drug particles in contact with the dissolution medium. ${ }^{31}$ Additionally, the slow release rate observed with formula $\mathrm{C} 1$ compared with formula C2 could be attributed to the larger particle size of $\mathrm{C}_{1}$ prepared with high molecular weight chitosan $(531 \mu \mathrm{m})$ in contrast to $\mathrm{C}_{2}$ prepared with low molecular weight chitosan $(364 \mu \mathrm{m})$. The larger particle size decreased the surface area available for dissolution and so decreased the release rate.

Figure $5 b$ shows the effect of the different concentrations of chitosan on the percentage drug released from the prepared microspheres. The percentage of drug released after $15 \mathrm{~min}$ from chitosan microspheres prepared with $1 \%\left(\mathrm{C}_{3}\right), 1.5 \%\left(\mathrm{C}_{4}\right)$ and $2 \% \mathrm{w} / \mathrm{v}\left(\mathrm{C}_{1}\right)$ chitosan in acetic acid were 35,30 and $25 \%$ respectively and increased to 49,46 and $42 \%$ after one hour. The microspheres prepared with $1 \%$ and $1.5 \%$ chitosan showed complete release (about $90 \%$ ) of the loaded drug after $6 \mathrm{hr}$, while the microspheres prepared with $2 \%$ chitosan gave complete release $(90 \%)$ after $8 \mathrm{hr}$.

Rapid drug release was obtained with low concentrations of chitosan which could be related to the lower viscosity of chitosan solution formed around drug particles. $^{36}$

The amount of cross-linking agent (glutaraldehyde) played an important role in the release of the drug from chitosan microspheres. It was observed that when the amount of cross-linking agent increased from $1 \mathrm{ml}\left(\mathrm{C}_{5}\right)$, $3 \mathrm{ml}\left(\mathrm{C}_{6}\right)$ to $5 \mathrm{ml}\left(\mathrm{C}_{1}\right)$ the percentage of drug released decreased from 38 and 33 to $25 \%$ after $15 \mathrm{~min}$ and 
from 53 and 47 to $43 \%$ after one hour respectively (Figure 5c). Furthermore, the microspheres prepared with $1 \mathrm{ml}$ and $3 \mathrm{ml}$ glutaraldehyde gave an almost complete release of about $90 \%$ of the loaded drug after $6 \mathrm{hr}$, however, the microspheres prepared with $5 \mathrm{ml}$ glutaraldehyde gave the same percentage of drug released after $8 \mathrm{hr}$ as shown in Figure 5c.

The percentage drug released from chitosan microspheres prepared after a cross-linking time of $1.5 \mathrm{hr}\left(\mathrm{C}_{7}\right)$ showed rapid release in comparison with the microspheres prepared after a cross-linking time of $3 \mathrm{hrs}\left(\mathrm{C}_{1}\right)$ as shown in Figure 5d. This figure illustrates that 32\% of the loaded drug was released after 15 min in case of formula $\left(\mathrm{C}_{7}\right)$ and about $50 \%$ was released in the first hour. Complete release $(90 \%)$ was obtained after $6 \mathrm{hr}$ (Figure 5d). It was obvious that drug release rate decreased with an increase in the amount and time of cross-linking agent. These results are similar to previous studies $^{31}$ stating that the porosity of chitosan microspheres containing phenobarbitone decreased by increasing the amount and time of cross linking agent.

The effect of using different acids as a solvent for chitosan polymer $\left(\mathrm{C}_{8}, \mathrm{C}_{9}, \mathrm{C}_{10}, \mathrm{C}_{11}\right)$ instead of acetic acid $\left(C_{1}\right)$ on the percentage drug released from the prepared microspheres is illustrated in Figure 5e. The microspheres prepared with lactic acid $\left(\mathrm{C}_{8}\right)$, propionic acid $\left(\mathrm{C}_{9}\right)$, citric acid $\left(\mathrm{C}_{10}\right)$ and formic acid $\left(\mathrm{C}_{11}\right)$ released about $50 \%$ of the loaded drug in the first hour and showed complete release after $6 \mathrm{hr}$, while the microspheres prepared using acetic acid released about $50 \%$ of the loaded drug after $2 \mathrm{hr}$ and gave complete release (90\%) after $8 \mathrm{hr}$ (Figure 5e).
The decrease in the drug release rate in case of chitosan dissolved in acetic acid compared with chitosan dissolved in other acids could be due to the higher viscosity of chitosan solution in acetic acid as previously explained. ${ }^{27}$ In addition, the decrease in the release rate observed with chitosan dissolved in acetic acid could be attributed to its larger particle size $(531 \mu \mathrm{m})$ in comparison with other acids.

\section{Kinetics of captopril release from chitosan microspheres}

Table 2 illustrates the linear correlation coefficients obtained for the three models tested (zero order, first order and Higuchi model). Highest correlation coefficients were found to fit well with Higuchi model $(\mathrm{r}=0.999 \pm 0.001)$. The linearity was also obtained when $\mathrm{dQ} / \mathrm{dt}$ was plotted against 1/Q. However, when $\mathrm{dQ} / \mathrm{dt}$ was plotted versus $\mathrm{Q}$, linearity was not obtained. This indicated that the release kinetics from microspheres was a near diffusion-controlled mechanism and the drug release from microspheres was dependent on its concentration.

\section{Swelling properties}

The swelling volume of the prepared chitosan microspheres after 1, 4, 8 and $24 \mathrm{hr}$ is illustrated in Figure 6. The microspheres prepared with high molecular weight chitosan $\left(\mathrm{C}_{1}\right)$ had a higher swelling volume (4 $\mathrm{ml})$ than the microspheres prepared with low molecular weight chitosan $\left(\mathrm{C}_{2}\right)$ whose swelling volume was 2 $\mathrm{ml}$ after $24 \mathrm{hr}$. Microspheres prepared with $2 \%$ chitosan $\left(C_{1}\right)$ showed a swelling volume of $4 \mathrm{ml}$ after $24 \mathrm{hr}$ which decreased to $3 \mathrm{ml}$ and $2 \mathrm{ml}$ for the microspheres

\begin{tabular}{|c|c|c|c|c|c|}
\hline \multicolumn{6}{|c|}{ Release kinetics \pm (S.D) } \\
\hline \multirow[t]{2}{*}{ Formulae } & \multirow{2}{*}{$\begin{array}{c}\text { Zero-order }\left(r^{\star}\right) \\
\% \text { released vs.time }\end{array}$} & \multicolumn{2}{|c|}{ First-order $\left(r^{*}\right)$} & \multicolumn{2}{|c|}{ Diffusion mechanism $\left(r^{\star}\right)$} \\
\hline & & $\begin{array}{c}\log \% \text { remained vs. } \\
\text { time }\end{array}$ & dQ/dt vs.Q & $\begin{array}{l}\% \text { released vs. } \\
\text { time }\end{array}$ & dQ/dt vs. $1 / Q$ \\
\hline C1 & $0.972 \pm 0.002$ & $0.946 \pm 0.006$ & $0.913 \pm 0.005$ & $0.995 \pm 0.001$ & $0.994 \pm 0.003$ \\
\hline $\mathrm{C} 2$ & $0.89 \pm 0.004$ & $0.874 \pm 0.007$ & $0.851 \pm 0.003$ & $0.9993 \pm 0.005$ & $0.997 \pm 0.004$ \\
\hline C3 & $0.95 \pm 0.001$ & $0.923 \pm 0.006$ & $0.892 \pm 0.001$ & $0.996 \pm 0.002$ & $0.995 \pm 0.003$ \\
\hline $\mathrm{C} 4$ & $0.959 \pm 0.004$ & $0.935 \pm 0.005$ & $0.915 \pm 0.007$ & $0.9954 \pm 0.001$ & $0.993 \pm 0.002$ \\
\hline C5 & $0.94 \pm 0.005$ & $0.924 \pm 0.003$ & $0.884 \pm 0.004$ & $0.998 \pm 0.006$ & $0.996 \pm 0.005$ \\
\hline C6 & $0.964 \pm 0.003$ & $0.937 \pm 0.002$ & $0.912 \pm 0.003$ & $0.9957 \pm 0.005$ & $0.9946 \pm 0.006$ \\
\hline $\mathrm{C} 7$ & $0.967 \pm 0.003$ & $0.93 \pm 0.004$ & $0.89 \pm 0.005$ & $0.9953 \pm 0.001$ & $0.9947 \pm 0.001$ \\
\hline C8 & $0.954 \pm 0.001$ & $0.925 \pm 0.005$ & $0.91 \pm 0.006$ & $0.997 \pm 0.002$ & $0.996 \pm 0.004$ \\
\hline C9 & $0.945 \pm 0.002$ & $0.913 \pm 0.002$ & $0.884 \pm 0.004$ & $0.998 \pm 0.004$ & $0.996 \pm 0.005$ \\
\hline C10 & $0.948 \pm 0.002$ & $0.92 \pm 0.007$ & $0.892 \pm 0.003$ & $0.9976 \pm 0.007$ & $0.995 \pm 0.006$ \\
\hline C11 & $0.939 \pm 0.006$ & $0.915 \pm 0.003$ & $0.89 \pm 0.005$ & $0.999 \pm 0.001$ & $0.9972 \pm 0.001$ \\
\hline
\end{tabular}

$r^{*}$ correlation coefficient 


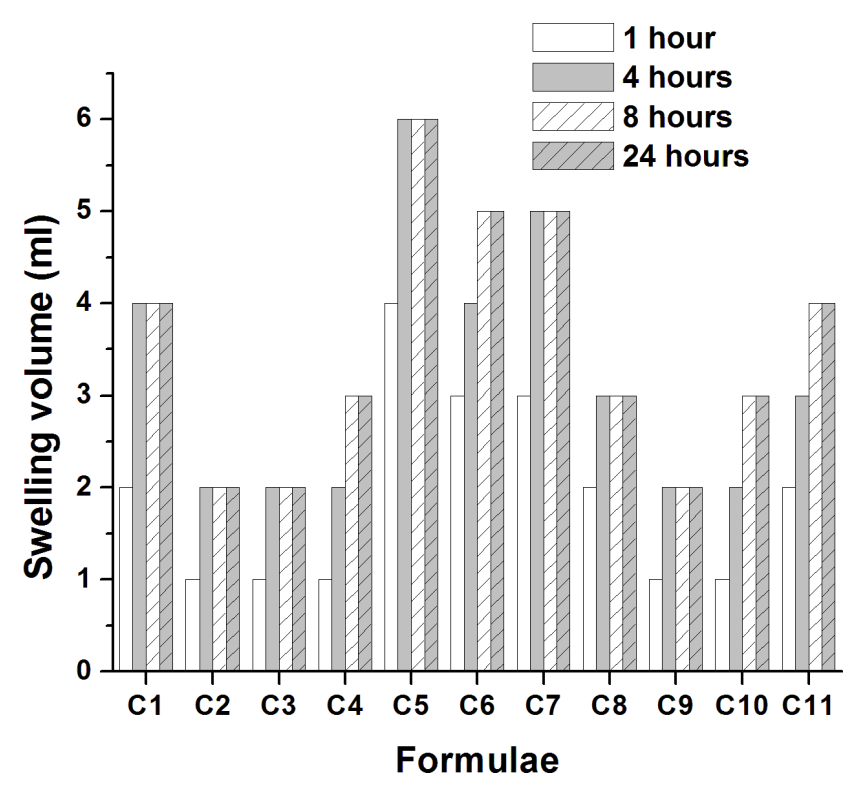

Figure 6: Swelling volumes $(\mathrm{ml})$ of the different chitosan microspheres at different time intervals.

prepared with $1.5 \%\left(\mathrm{C}_{4}\right)$ and $1 \%\left(\mathrm{C}_{3}\right)$ chitosan respectively. The results showed that the microspheres prepared with acetic acid $\left(\mathrm{C}_{1}\right)$ exhibited a swelling volume of $4 \mathrm{ml}$ after $24 \mathrm{hr}$, while, the microspheres prepared with lactic acid $\left(\mathrm{C}_{8}\right)$, propionic acid $\left(\mathrm{C}_{9}\right)$, citric acid $\left(\mathrm{C}_{10}\right)$ and formic acid $\left(\mathrm{C}_{11}\right)$, showed a swelling volume of $3,2,3 \mathrm{ml}$ and $4 \mathrm{ml}$ after $24 \mathrm{hr}$ respectively. All these results might due to the increase in porosity of the chitosan microspheres prepared with $2 \%$ high molecular weight chitosan in acetic acid. This increase in porosity resulted in an increased water intake by the microspheres and consequently increased the swelling volume..$^{37,38}$

By increasing the cross-linking amount from $1 \mathrm{ml}\left(\mathrm{C}_{5}\right)$, $3 \mathrm{ml}\left(\mathrm{C}_{6}\right)$ to $5 \mathrm{ml}\left(\mathrm{C}_{1}\right)$ the swelling volume decreased from $6 \mathrm{ml}$ and $5 \mathrm{ml}$ to $4 \mathrm{ml}$ respectively. Furthermore, the increase in cross-linking time from $1.5 \mathrm{hr}\left(\mathrm{C}_{7}\right)$ to $3 \mathrm{hr}$ $\left(\mathrm{C}_{1}\right)$ decreased the swelling volume from $5 \mathrm{ml}$ to $4 \mathrm{ml}$ after $24 \mathrm{hr}$. The decreased swelling volume resulting from increased cross-linking agent and cross-linking time might also be referred to the increase in crosslinking between the chitosan molecules which in turn decreased the swellability of the microspheres. These results are in agreement with previously reported studies $35,37,38$

\section{In-vitro determination of Bioadhesive properties of chitosan microspheres}

The bioadhesive values of chitosan microspheres are illustrated in Figure 7. As seen in this figure formula $\left(\mathrm{C}_{5}\right)$ of chitosan microsphere showed the highest bioadhesive percent $(78 \%)$ while the lowest bioadhesive percent $(55 \%)$ was observed for formula $\mathrm{C}_{2}$. As reported

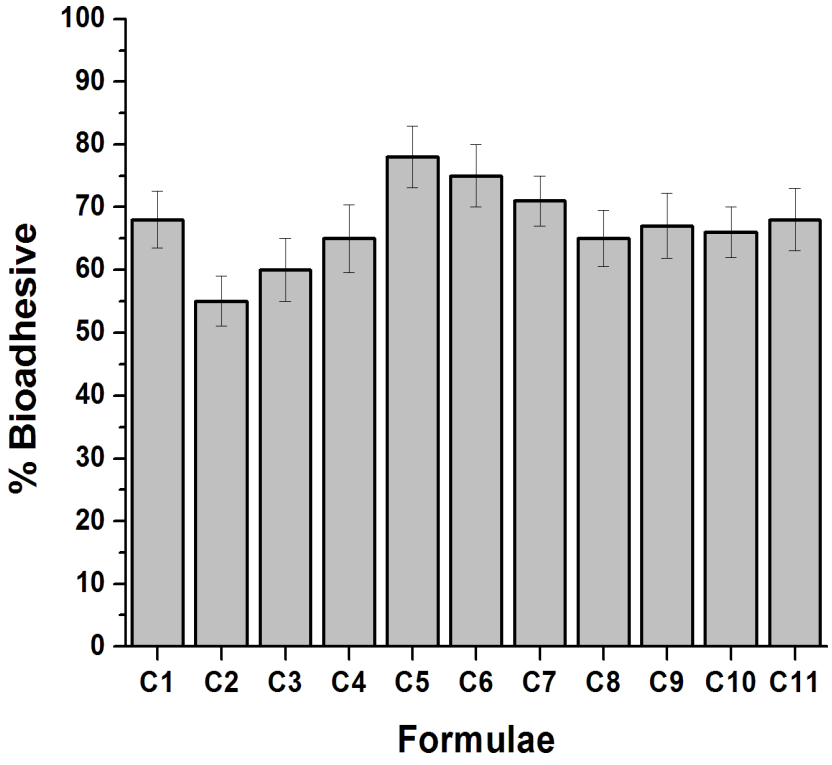

Figure 7: Percentage bioadhesive of the different chitosan microspheres $(n=3)$.

before, two important factors affect the bioadhesive properties of chitosan microspheres, the swelling volume and the amount of glutaraldehyde used in the preparation of microspheres..$^{39,40}$ Accordingly, formula $\mathrm{C}_{5}$ showed the highest bioadhesive percent since the highest swelling volume was observed for this formula. This high swelling volume facilitated interpenetration of mucus and made bioadhesion stronger. Additionally, formula $\mathrm{C}_{5}$ was prepared with the lowest amount of glutaraldehyde and consequently, the cross-linking between chitosan molecules was weak which increased the bioadhesion property of this formula. Furthermore, it was previously reported that glutaraldehyde reduces the affinity of chitosan polymer for mucin and depresses its mucoadhesive properties. ${ }^{40}$ Thus, decreasing the amount of glutaraldehyde employed leads to increase the bioadhesion property of this formula.

\section{CONCLUSION}

Chitosan microspheres prepared with $2 \%$ high molecular weight chitosan in acetic acid with $5 \mathrm{ml}$ glutaraldehyde and a cross-linking time $3 \mathrm{hr}$ (formula $\mathrm{C}_{1}$ ) gave the highest yield percent $(83 \%)$, largest particle size $(531 \mu \mathrm{m})$ and sustained release over $8 \mathrm{hr}$. Although decreasing the cross-linking time and amount of cross-linking agent showed excellent bioadhesive properties, the drug release was very rapid. Accordingly, formula $C_{1}$ which gave the slowest release rate and the highest entrapment efficiency could be considered as a promising carrier for captopril for further clinical investigations. 


\section{CONFLICT OF INTEREST}

The authors report no conflicts of interest. The authors alone are responsible for the content and writing of this article.

\section{ABBREVIATIONS}

HPMC: hydroxypropyl methylcellulose;

EE: entrapment efficiency.

\section{REFERENCES}

1. Robinson EL, Greenfield SA. The effect of captopril on the membrane properties of central neurons in-vitro. J Pharm Pharmacol. 1990;42(1):20-5.

2. Duchin KL, McKinstry DN, Cohen Al, Migdalof BH. Pharmacokinetics of captopril in healthy subjects and in patients with cardiovascular diseases. Clin Pharmacokinet. 1988;14(4):241-59.

3. Cohen ML, Kurz K. Captopril and MK-421: Stability on storage, distribution to the central nervous system and onset of activity. Fed Proc. 1983;42(2):171-5.

4. Lee JH, Park TG, Choi HK. Development of oral drug delivery system using floating microspheres. J Microencapsul. 1999;16(6):715-29.

5. Nur AO, Zhang JS. Captopril floating and/or bioadhesive tablets: Design and release kinetics. Drug Dev Ind Pharm. 2000;26(9):965-9.

6. Ichikawa M, Watanabe S, Miyake Y. A new multiple-unit oral floating dosage system. I: Preparation and in vitro evaluation of floating and sustainedrelease characteristics. J Pharm Sci. 1991;80(11):1062-6.

7. Okada $\mathrm{H}$, Toguchi $\mathrm{H}$. Biodegradable microspheres in drug delivery. Crit Rev Ther Drug Carrier Syst. 1995;12(1):1-99.

8. Crotts G, Park TG. Protein delivery from poly(lactic-co-glycolic acid) biodegradable microspheres: Release kinetics and stability issues. J Microencapsul. 1998;15(6) : :699-713.

9. Kas HS. Chitosan: Properties, preparations and application to microparticulate systems. J Microencapsul. 1997;14(6):689-711.

10. Sabnis S, Rege P, Block LH. Use of chitosan in compressed tablets of diclofenac sodium: Inhibition of drug release in an acidic environment. Pharm Dev Technol. 1997;2(3):243-55

11. Aiedeh K, Gianasi E, Orienti I, Zecchi V. Chitosan microcapsules as controlled release systems for insulin. J Microencapsul. 1997;14(5):567-76.

12. Mi FL, Wong TB, Shyu SS. Sustained-release of oxytetracycline from chitosan microspheres prepared by interfacial acylation and spray hardening methods. J Microencapsul. 1997;14(5):577-91

13. Jameela SR, Kumary TV, Lal AV, Jayakrishnan A. Progesterone-loaded chitosan microspheres: A long acting biodegradable controlled delivery system. J Control Release. 1998;52(1-2):17-24.

14. Felt $\mathrm{O}$, Buri $\mathrm{P}$, Gurny R. Chitosan: A unique polysaccharide for drug delivery. Drug Dev Ind Pharm. 1998;24(11):979-93.

15. Remunan-Lopez C, Portero A, Vila-Jato JL, Alonso MJ. Design and evaluation of chitosan/ethylcellulose mucoadhesive bilayered devices for buccal drug delivery. J Control Release. 1998;55(2-3):143-52.

16. Bernkop-Schnurch A, Krajicek ME. Mucoadhesive polymers as platforms for peroral peptide delivery and absorption: Synthesis and evaluation of different chitosan-EDTA conjugates. J Control Release. 1998;50(1-3):215-23.

17. Rihova B, Rathi RC, Kopeckova P, Kopecek J. Bioadhesive polymers for oral drug delivery. Adv Exp Med Biol. 1995;371B:1491-4.

18. Leong KW, Mao HQ, Truong-Le VL, Roy K, Walsh SM, August JT. DNApolycation nanospheres as non-viral gene delivery vehicles. J Control Release. 1998;53(1-3):183-93.
19. Akbuga J, Bergisadi N. 5-Fluorouracil-loaded chitosan microspheres: Preparation and release characteristics. J Microencapsul. 1996;13(2):161-8.

20. Cosco D, Failla P, Costa N, Pullano S, Fiorillo A, Mollace V, et al. Rutinloaded chitosan microspheres: Characterization and evaluation of the antiinflammatory activity. Carbohydr Polym. 2016;152:583-91.

21. Lee JH, Park TG, Lee YB, Shin SC, Choi HK. Effect of adding non-volatile oil as a core material for the floating microspheres prepared by emulsion solvent diffusion method. J Microencapsul. 2001;18(1):65-75.

22. Gupta PK, Hung CT, Perrier DG. Quantitation of the release of doxorubicin from colloidal dosage forms using dynamic dialysis. Int J Pharm. 1986;33:137-40

23. Higuchi T. Mechanism of Sustained-Action Medication: Theoretical Analysis of Rate of Release of Solid Drugs Dispersed in Solid Matrices. J Pharm Sci. 1963;52:1145-9

24. Samuelov $Y$, Donbrow M, Friedman M. Sustained release of drugs from ethylcellulose--polyethylene glycol films and kinetics of drug release. $J$ Pharm Sci. 1979;68(3):325-9.

25. Hassan EE, Parish RC, Gallo JM. Optimized formulation of magnetic chitosan microspheres containing the anticancer agent, oxantrazole. Pharm Res. 1992;9:390-7.

26. Barip RRKVa. A novel in situ method to test polymers and coated microparticles for bioadhesion. Int J Pharm. 1989;52(3):265-70.

27. Singla AK, Sharma ML, Dhawan S. Nifedipine loaded chitosan microspheres: Characterization of internal structure. Biotech Histochem. 2001;76(4):165-71.

28. Denkbas EB, Seyyal M, Piskin E. 5-fluorouracil loaded chitosan microspheres for chemoembolization. J Microencapsul. 1999;16(6):741-9.

29. Sankar C, Rani M, Srivastava AK, Mishra B. Chitosan based pentazocine microspheres for intranasal systemic delivery: Development and biopharmaceutical evaluation. Pharmazie. 2001;56(3):223-6.

30. Shi X, Fang Q, Ding M, Wu J, Ye F, Lv Z, et al. Microspheres of carboxymethyl chitosan, sodium alginate and collagen for a novel hemostatic in vitro study. J Biomater Appl. 2016;30(7):1092-102.

31. al-Helw AA, Al-Angary AA, Mahrous GM, Al-Dardari MM. Preparation and evaluation of sustained release cross-linked chitosan microspheres containing phenobarbitone. J Microencapsul. 1998;15(3):373-82.

32. Abd-Allah $\mathrm{H}$, Kamel $\mathrm{AO}$, Sammour $\mathrm{OA}$. Injectable long acting chitosan/ tripolyphosphate microspheres for the intra-articular delivery of lornoxicam: Optimization and in vivo evaluation. Carbohydr Polym. 2016;149:263-73.

33. Chen MM, Cao H, Liu YY, Song FF, Chen JD, et al. Sequential delivery of chlorhexidine acetate and bFGF from PLGA-glycol chitosan core-shell microspheres. Colloids Surf B Biointerfaces. 2017;151:189-95.

34. Shan L, Tao EX, Meng QH, Hou WX, Liu K, Shang HC, et al. Formulation, optimization and pharmacodynamic evaluation of chitosan/phospholipid/ beta-cyclodextrin microspheres. Drug Des Devel Ther. 2016;10:417-29.

35. Thanoo BC, Sunny MC, Jayakrishnan A. Cross-linked chitosan microspheres: Preparation and evaluation as a matrix for the controlled release of pharmaceuticals. J Pharm Pharmacol. 1992;44(4):283-6.

36. Nishioka Y, Kyotani S, Okamura M, Miyazaki M, Okazaki K, Ohnishi S, et al. Release characteristics of cisplatin chitosan microspheres and effect of containing chitin. Chem Pharm Bull. 1990;38(10):2871-3.

37. Funes A, DeVicente J, DeVicente I. Synthesis and characterization of magnetic chitosan microspheres as low-density and low-biotoxicity adsorbents for lake restoration. Chemosphere. 2017;171:571-9.

38. Ganguly K, Kulkarni AR, Aminabhavi TM. In vitro cytotoxicity and in vivo efficacy of 5-fluorouracil-loaded enteric-coated PEG-cross-linked chitosan microspheres in colorectal cancer therapy in rats. Drug Deliv. 2016;23:2838-51.

39. Patashnik S, Rabinovich L, Golomb G. Preparation and evaluation of chitosan microspheres containing bisphosphonates. J Drug Target. 1997;4(6):371-80.

40. Bottenberg P, Cleymaet R, DeMuynck C, Remon JP, Coomans D, Michotte Y, et al. Development and testing of bioadhesive, fluoride-containing slowrelease tablets for oral use. J Pharm Pharmacol. 1991;43(7)f:457-64. 
PICTORIAL ABSTRACT
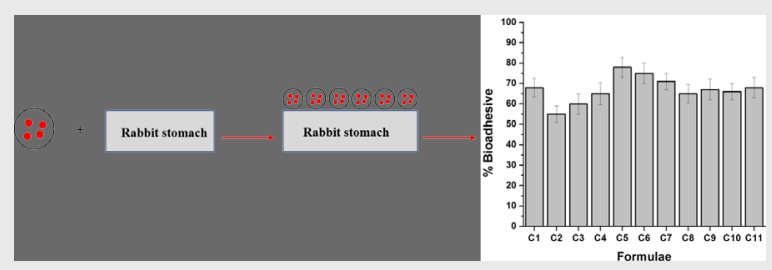

\section{SUMMARY}

The slowest captopril release, the highest yield percent and the highest entrapment efficiency were observed for chitosan microspheres which were prepared with $2 \%$ high molecular weight chitosan in acetic acid with $5 \mathrm{ml}$ glutaraldehyde and a crosslinking time $3 \mathrm{hr}$

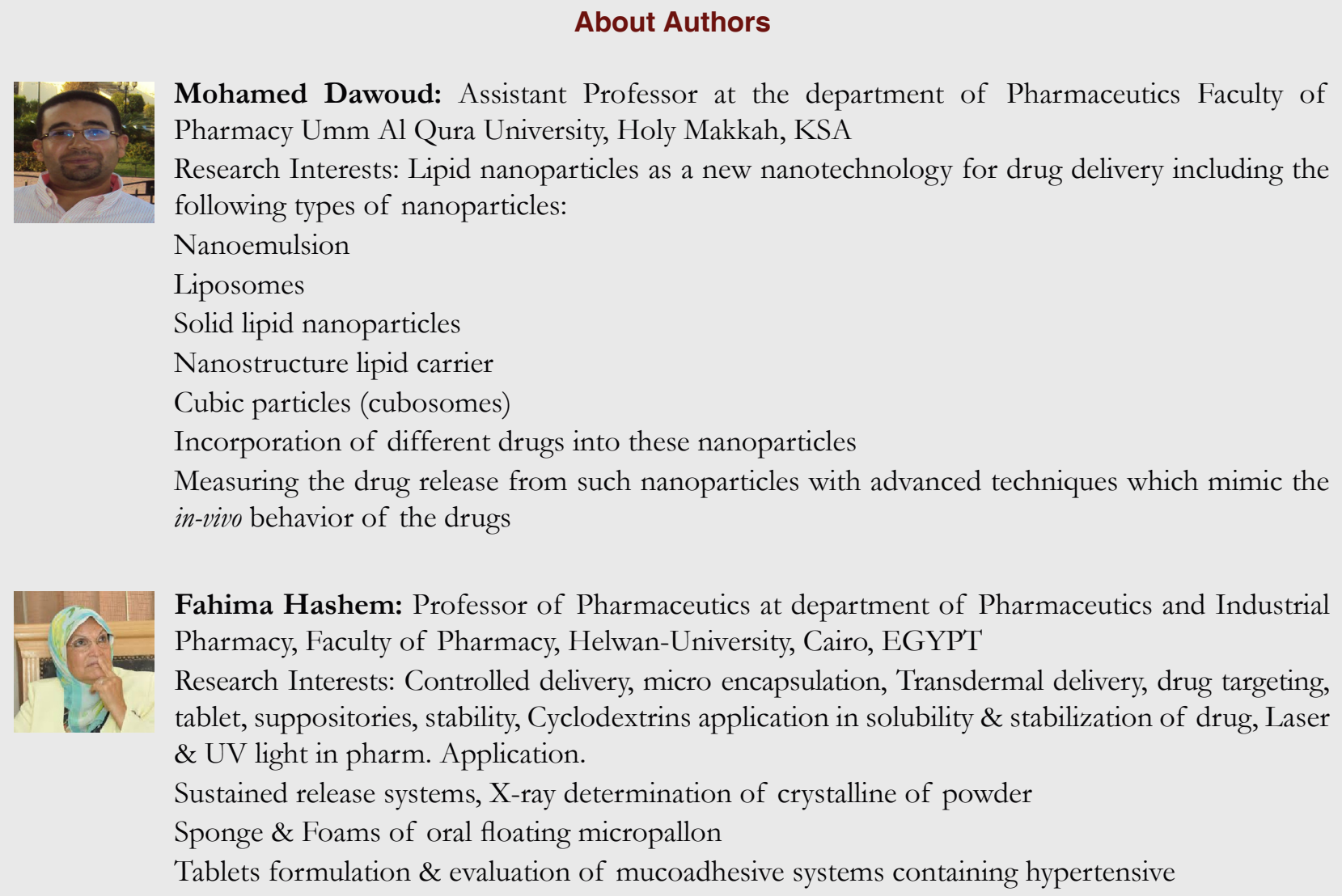

Mohamed Dawoud: Assistant Professor at the department of Pharmaceutics Faculty of Pharmacy Umm Al Qura University, Holy Makkah, KSA

Research Interests: Lipid nanoparticles as a new nanotechnology for drug delivery including the following types of nanoparticles:

Nanoemulsion

Liposomes

Solid lipid nanoparticles

Nanostructure lipid carrier

Cubic particles (cubosomes)

Incorporation of different drugs into these nanoparticles

Measuring the drug release from such nanoparticles with advanced techniques which mimic the in-vivo behavior of the drugs

Fahima Hashem: Professor of Pharmaceutics at department of Pharmaceutics and Industrial Pharmacy, Faculty of Pharmacy, Helwan-University, Cairo, EGYPT

Research Interests: Controlled delivery, micro encapsulation, Transdermal delivery, drug targeting, tablet, suppositories, stability, Cyclodextrins application in solubility \& stabilization of drug, Laser \& UV light in pharm. Application.

Sustained release systems, X-ray determination of crystalline of powder

Sponge \& Foams of oral floating micropallon

Tablets formulation \& evaluation of mucoadhesive systems containing hypertensive

Cite this article: Dawoud M, Hashem F. Formulation and in-vitro Evaluation of Oral Captopril Bioadhesive Delivery System. Indian J of Pharmaceutical Education and Research. 2020;54(2s):s200-s209. 